\title{
Rharodesmus tabarkensis n. sp., a new pyrgodesmid from Tunisia (Diplopoda: Polydesmida)
}

\author{
NESRINE AKKARI \& HENRIK ENGHOFF \\ Natural History Museum of Denmark (Zoological Museum), University of Copenhagen, Universitetsparken 15, DK-2100 Kфbenhavn \\ $\emptyset$-Denmark.E-mail: nakkari@snm.ku.dk
}

Recently, we (Akkari \& Enghoff 2011) described a new species of the genus Rharodesmus Schubart, 1960, discussing the taxonomic state of the family Pyrgodesmidae and providing notes on the four genera occurring in the west Palaearctic area. However, we failed to present details on the holotype of the new species, which we now provide in this note in order to make the species name available. Thus, we describe here the new species Rharodesmus tabarkensis Akkari \& Enghoff by reference to the full description given in Akkari \& Enghoff (2011) with the following information on the type material: Holotype $\hat{\delta}$, TUNISIA, NW, Jendouba Governorate, Tabarka, N36 57.8 , E8 44.6 , alt. < 40 m, coastal slope below the Genoese fort, under stones, 9.iii.2009, N. Akkari \& H. Enghoff leg. (Natural History Museum of Denmark, Zoological Museum, University of Copenhagen, - ZMUC); Paratypes: 12 $\widehat{\jmath}, 8$ $q$, 14 juveniles, same locality and date as holotype, N. Akkari \& H. Enghoff leg. (ZMUC).

\section{Reference}

Akkari, N. \& Enghoff, H. (2011) Rharodesmus Schubart, 1960 - a tropical element in the North African fauna: a new species from Tunisia and notes on the family Pyrgodesmidae (Diplopoda: Polydesmida). Zootaxa, 2985, 55-63. 